Usos del totalitarismo en la Argentina:

recepciones, conceptualizaciones y polémicas político-intelectuales 


\section{Usos del totalitarismo en Argentina: recepciones, conceptualizaciones y polémicas político-intelectuales}

Martín Vicente ${ }^{1}$

\section{Presentación}

as miradas y construcciones discursivas sobre los fenómenos totalitarios en L Argentina estuvieron marcadas por las complejidades histórico-políticas en las que diversos intelectuales, políticos y académicos elaboraron (y reelaboraron) teorías, ensayaron caracterizaciones o cruzaron acusaciones. Lejos de alejarse de los usos políticos inmediatos y normalizarse en paralelo a lo que ocurría en la producción ensayística y académica de Europa y Estados Unidos, las problematizaciones en el contexto argentino, hasta entrados los años de la transición democrática iniciada a finales de 1983, mantuvieron un tono centralmente polémico. ${ }^{2}$ Si la década de 1930 vio las primeras reflexiones locales sobre la cuestión, en la misma etapa de la aparición del concepto en la Italia gobernada por el fascismo, aún los años de la última dictadura, entre 1976 y 1983, fueron un contexto fértil para que los usos del término operasen como modos de leer la política nacional e internacional, así como los vínculos entre ambas. Aproximadamente cincuenta años, entonces, como son abordados por los artículos que aquí se presentan, de usos diversos de un concepto que atravesó el siglo XX occidental como una categoría ético-política central, implican un interesante terreno para la indagación por los tipos de inflexiones conceptuales en un marco complejo e inestable como el de la Argentina de esas décadas.

\footnotetext{
1 Universidad Nacional de General Sarmiento/Consejo Nacional de Investigaciones Científicas y Técnicas. Argentina. Correo electrónico: vicentemartin28@gmail.com

2 Como se podrá observar, los artículos aquí incluidos, que se centran en usos polémicos del término, no abordan el período de la reconstrucción democrática abierta en 1983, cuando puede apreciarse una normalización del concepto.
} 
El avance de los fascismos y los nacionalismos autoritarios en el Viejo Continente despertaron la atención de varios intelectuales y políticos argentinos, tanto de quienes miraron con interés las expresiones europeas como modelos posibles de replicar en el país como de aquellos que conformaron el heterogéneo frente antifascista local. Al mismo tiempo, los debates sobre el totalitarismo en ese contexto reformularon muchas de las lecturas sobre el proceso soviético, colocando a la democracia liberal como modelo equidistante de ambos extremismos. La alternancia entre gobiernos surgidos del voto universal, dictaduras y gobiernos bajo regímenes de exclusión que caracterizó al orden político argentino desde 1930 y hasta 1983 implicó, así, un arco especialmente sugestivo para que diversas voces formularan sus lecturas sobre el totalitarismo como un problema que tenía (o podía tener) directa vinculación con la realidad política del país.

La producción académica en Argentina, sin embargo, no se ha internado en la problemática del totalitarismo como un tema de especial relevancia: pocos trabajos se han encargado de abordar los usos conceptuales, las recepciones teóricas o las polémicas políticas e intelectuales que el concepto ha recibido en el país. ${ }^{3}$ Diversas investigaciones han atendido, no obstante, a ciertos aspectos de la problemática del totalitarismo, si bien como parte de proyectos o intereses mayores: en tal sentido, podemos mencionar como ejemplos los varios análisis sobre las derechas y los conflictos ideológicos durante la Guerra Fría, que han abordado algunos ejes de la cuestión (Bohoslavsky, 2009), así como lo han hecho algunos trabajos abocados al conflicto entre peronismo y antiperonismo (Martínez Mazzola, 2011) o la modernización intelectual de mediados de siglo (Blanco, 2006). Como podrá verse a lo largo del dossier, los artículos aquí incluidos dialogan con esos antecedentes, al tiempo que abren nuevas líneas plausibles de continuarse en trabajos posteriores y se entroncan con preocupaciones presentes en estudios previos de los autores que aquí intervienen.

El artículo de Olga Echeverría que abre el dossier aborda el caso de monseñor Gustavo Franceschi. El referente católico ha sido analizado por diversas investigaciones, especialmente por el peso de su figura como director de la revista Criterio, señera del universo intelectual confesional. En los últimos años, una serie de nuevas miradas han renovado los modos de aproximarse a la compleja figura del prelado e intelectual, y en tal sentido este trabajo se entronca en dicha línea: Echeverría, desde el tópico del totalitarismo, aborda

\footnotetext{
3 Existe, más allá de los objetivos de este dossier, producción de investigadores que han analizado la cuestión del totalitarismo desde problemáticas propias de la Filosofía Política. Autores como Jorge Dotti, Claudia Hilb, Martín Plot, entre otros, pueden mencionarse en esta línea.
} 
las concepciones políticas de Franceschi en una etapa especialmente compleja como la de las décadas de 1920 a 1940, con especial atención al contexto de lo que Enzo Traverso (2009) ha denominado "la guerra civil europea". Echeverría coloca a Franceschi dentro del universo católico y del mundo de las derechas nacionalistas, atendiendo al tipo de relaciones político-conceptuales que el sacerdote y ensayista construyó entre dichas esferas. Tanto desde las páginas de Criterio como desde sus libros y notas en otras publicaciones, Franceschi publicó interpretaciones sobre la problemática totalitaria en vínculo con varios de los temas que cruzaban sus inquietudes en torno al orden político en la Modernidad. En las lecturas del director de Criterio las cuestiones políticas aparecían en vínculo con sus consideraciones sobre el lugar del catolicismo y la Iglesia en la vida de las sociedades. Si bien Echeverría señala (en coincidencia con lo marcado previamente por otros trabajos) que Franceschi se mostró favorable a las experiencias nacionalistas europeas, la autora destaca que este consideraba inevitable el orden democrático, desde una interpretación sumamente personal de la democracia y sus vínculos con la fe. Así, la historiadora enfoca una clave de lectura sugerente: para Franceschi el punto clave de los totalitarismos no se hallaba en las formas de gobierno sino en las relaciones que el Estado establecía con los sujetos ("la persona humana" en los términos del humanismo católico) y con Dios.

En la reconstrucción del pensamiento del sacerdote sobre la problemática totalitaria, Echeverría atiende a distintos focos: desde los viajes de Franceschi a Europa durante el ascenso de los fascismos a las comparaciones entre estos y el sistema soviético, de las relaciones entre la Modernidad y el totalitarismo a los modos de interpretar la situación argentina desde las consideraciones sobre las facetas de la problemática totalitaria.

Andrés Bisso, por su parte, centra su trabajo en la literatura antiperonista, entendida como un fenómeno del contexto abierto con el derrocamiento del segundo gobierno de Juan Domingo Perón en 1955. El artículo aborda las concepciones sobre el totalitarismo presentes en el universo del antiperonismo desde el volumen Frente al totalitarismo peronista, de Reynaldo Pastor, publicado en 1959. El ensayo del político e intelectual cuyano es ubicado por el autor en el "marco triunfante" en el cual figuras del antifascismo argentino reconvertidas al antiperonismo produjeron una serie de intervenciones críticas sobre la experiencia justicialista. El amplio espacio antiperonista (que Bisso indaga desde otros referentes como el liberal Federico Pinedo, quien escribió el prólogo del trabajo de Pastor, y el socialista Américo Ghioldi) prolongó desde allí lecturas sobre el peronismo que ya habían aparecido durante la etapa gubernamental justicialista, tanto como desarrolló otras de carácter novedoso. 
Bisso coloca las estrategias de Pastor como un modo de entroncar las posiciones antiperonistas con las antitotalitarias, estirando el concepto hacia lecturas capaces de englobar otros fenómenos políticos, en una matriz interpretativa que podía ir del frondizismo en Argentina al nasserismo en Egipto, pasando por la renovación internacional de las izquierdas.

El conservador Pastor, señala el autor, se mostró especialmente interesado en construir una lectura vinculante del régimen soviético y el peronismo, a los que veía unidos por posiciones políticas, económicas y sociales, a la vez que trazaba una línea común entre estos, el gobierno de Juan Manuel de Rosas en el siglo XIX y los fascismos. En la interpretación del sanjuanino, entonces, el totalitarismo podía obedecer tanto a un fenómeno propio del siglo XX como hundir sus raíces en casos pretéritos como el de "la primera tiranía", tal como se calificaba a la etapa rosista en el universo antiperonista.

El marco de relaciones políticas y de interpretaciones conceptuales donde una lectura como la de Pastor se tramó en el momento posperonista no será, sin embargo, inmune al fracaso de la experiencia de la autodenominada Revolución Libertadora que derrocó al justicialismo y a las fracturas del universo antiperonista. Tal como han comenzado a marcar estudios de los últimos años, también aquí el autor coloca su enfoque en las rupturas de un espacio antes abroquelado en la oposición a Perón, en este caso enfocando la problemática económica: mientras el antiperonismo socialista defendía posiciones intervencionistas, el puntano se acercaba a posturas convergentes con las de la renovación liberal, que en este caso Bisso compara con las de Friedrich von Hayek (un autor central para el artículo de Morresi y Vicente). En tal sentido, el análisis del historiador propone una lectura dinámica de cómo Pastor puede entroncar su análisis en los vínculos taxativos del antifascismo con el antitotalitarismo y también exponer una diversidad de puntos que marcan las particularidades de cómo este conservador narraba al peronismo desde la clave interpretativa del totalitarismo.

Laura Rodríguez, por su parte, aborda la figura de Antonio Caponnetto y, a través de él, ilumina una amplia red de intelectuales y publicaciones vinculadas con el pensamiento tradicionalista católico (que, como aclara, debe entenderse sin embargo desde su "heterogeneidad relativa"). La autora se centra en articular las propuestas de una obra clave del pedagogo, Pedagogía y Educación, publicada en 1981. Rodríguez reconstruye el modelo educativo ponderado por Caponnetto como modo de enfrentar lo que el autor presentaba como las alternativas totalitarias de la Modernidad. La cuestión educativopedagógica fue clave para un conjunto de intelectuales y expertos que, como marca el artículo, compartieron redes, circulaciones, conceptualizaciones y 
usos polémicos dentro de espacios académicos, intelectuales, políticos, religiosos de los que formaban parte, tanto desde instituciones estatales como por medio de publicaciones y contactos personales de diversa índole, especialmente con los actores españoles nucleados en torno a la revista Verbo. Así, Rodríguez analiza las posiciones de Caponnetto no solo dentro de una serie de redes e influencias, sino cotejando cómo este intelectual hacía uso de las propuestas de autores, manuales y libros orientados a la formación básica, exponiendo un arco de lecturas del autor tradicionalista desde lo ideológico a lo programático.

La corriente de la "Nueva Pedagogía", el educador brasileño Paulo Freire, los expertos de la Organización de las Naciones Unidas para la Educación, la Ciencia y la Cultura (UNESCO) y las teorizaciones del suizo Jean Piaget son focos atendidos por Rodríguez para exponer cómo Caponnetto elegía blancos de sus críticas contra los modelos que entendía como contrarios a su propuesta y portavoces (directos o indirectos) de modelos totalitarios, donde las diferentes vertientes de izquierda, el liberalismo e incluso la propia democracia eran colocados como amenazas. A diferencia de los demás trabajos del dossier, la autora no centra el análisis en las problemáticas del orden político (que tienen su lugar en el artículo) o el sistema democrático sino en el peso de la educación en la formación de sujetos, un tópico que fue central en la producción del nacionalismo católico, como las investigaciones previas de la propia Rodríguez lo han marcado. Por lo tanto, el artículo muestra también de qué manera muchas de las preocupaciones presentes en el espacio del tradicionalismo católico se expresaron como políticas públicas en la última dictadura o buscaron transformarse en plataformas para intervenir en diversas áreas del quehacer educativo.

El artículo de Martín Vicente y Sergio Morresi, finalmente, sale de la óptica presente en los demás trabajos, centrados sobre autores particulares y que desde allí se abren hacia redes o cruces, para atender a un grupo de actores intelectuales liberal-conservadores argentinos entre el derrocamiento del primer peronismo y su retorno al poder en 1973. En este caso, la investigación articula las alternativas del desarrollo de las teorías sobre el totalitarismo en la academia de Europa y Estados Unidos dentro del amplio universo liberal con los usos que estas recibieron en el país y los particulares modos en que el espacio liberal-conservador construyó desde allí una lectura vincular entre los fascismos, el comunismo y los populismos. La recepción y adaptación selectiva de los debates internacionales por parte del liberal-conservadurismo argentino, por lo tanto, enfatizó ciertos aspectos (como la potencialidad totalitaria de los regímenes democráticos) al tiempo que obturó otros (como las diferencias entre absolutismo y totalitarismo). En esta adaptación, los populismos (especialmente el peronismo) fueron entendidos como fenómenos que debían controlarse en 
pos de evitar que la democracia se pervirtiera en totalitarismo.

Los diversos espacios antiperonistas, como puede verse en el artículo de Bisso, habían planteado una lectura vincular entre populismo y totalitarismo, pero dentro de ese universo amplio, los intelectuales liberal-conservadores articularon una serie de problematizaciones que marcó sus concepciones sobre el orden político local en la etapa considerada. Una concepción binaria de la democracia, por lo tanto, fue la clave interpretativa que organizó las intervenciones de estos actores: por un lado, promovieron una forma democrática liberal y republicana y, por el otro, advirtieron sobre una vertiente populista que entendieron como peligrosa y capaz de transformar, desde adentro, a las propias sociedades democráticas en sistemas totalitarios.

El vínculo entre los artículos que componen este dossier, por lo tanto, implican centralmente una serie de diálogos sobre tres puntos. En primer término, la amplitud temporal cubierta por los trabajos, que abarcan un espacio de cinco décadas, trazan un arco amplio que permite atender a los cambios, continuidades y quiebres experimentados por los usos conceptuales y polémicos del término totalitarismo en un período extenso sumamente complejo. En segundo lugar, abordan desde distintos ángulos las problemáticas de los usos del totalitarismo en el espacio de diversas derechas argentinas: desde el catolicismo integrista (pero que veía a la democracia como horizonte epocal) de Franceschi al pensamiento reaccionario de Caponnetto y las redes pedagógicas del tradicionalismo católico, pasando por inflexiones propias de las derechas moderadas (muchas veces con vocación centrista) como las de los intelectuales liberal-conservadores y el conservadurismo antiperonista de Pastor y el antifascismo-antiperonismo. Tercero, en los artículos puede verse cómo diferentes actores de espacios intelectuales diferenciados expusieron la recepción de teorizaciones, polémicas y líneas temáticas creadas centralmente en Europa y Estados Unidos y adaptaron y resignificaron en el contexto nacional aquellas pautas.

Los trabajos aquí presentados, constituyen una de las entradas posibles a una cuestión que en el espacio académico argentino aparece, como marcamos, escasamente atendida hasta el momento. Temas como las recepciones y usos del totalitarismo en otros universos ideológicos (las izquierdas, los populismos, vertientes de derecha aquí no atendidas), los derroteros institucionales del concepto (en partidos políticos, legislación o instituciones estatales y sociales), la normalización académica tras el retorno democrático, entre otros tópicos, aparecen como líneas de investigación posibles que implicarían aportes de interés en pos de la conformación de un corpus académico de mayor densidad. 


\section{Referencias bibliográficas}

1. Blanco, A. (2006). Razón y modernidad. Gino Germani y la sociología en la Argentina. Buenos Aires, Argentina: Siglo XXI.

2. Bohoslavsky, E. (2009). ¿Partido de la democracia o agente del totalitarismo? Las derechas argentinas y brasileñas frente al comunismo en los orígenes de la guerra fría. Ponencia presentada en la XII Jornadas Interescuelas/ Departamento de Historia. Bariloche, 28 al 31 de octubre, Universidad Nacional del Comahue.

3. Martínez Mazzola, R. (2011). Nacionalismo, peronismo, comunismo. Los usos del totalitarismo en el discurso del Partido Socialista Argentino (1946-1953). Prismas, 15, 105-125.

4. Traverso, E. (2009). A sangre y fuego. De la guerra civil europea, 1914-1945. Buenos Aires, Argentina: Prometeo. 